Open Access

\title{
The official trilogy and public paradox: understanding mainland Chinese policies of ELT on secondary level from the perspective of culture politics
}

Fuli Liu(D)

Correspondence: frankliu@swu.edu.cn

College of International Studies, Southwest University, Chongqing, China

\begin{abstract}
The history of English test reform on secondary level in China is a reflection of Chinese development in recent 30 years. The stress on English language helps move on Chinese reform-and-open process. On the new historical step, there are some criticisms of English language and English language education in China. Particularly some people hold that it is necessary to reform the English tests, to re-understand the significance of English, and to lower down its weight in education. Meanwhile some others still emphasize the importance of English language and English language education in China, refusing to weaken the status of English in school education. The two trends of thinking could be explained by the cultural politics of English education in mainland China.

Though English helps in Chinese reform-and-open history, it produces difficulty in education because of its role as a foreign language, and it would bring about some possible problem in the field of ideology.
\end{abstract}

Keywords: ELT, Reform, Foreign language policy, Culture politics

\section{Background}

For over 30 years, Chinese policies of English language education, particularly the national direction of NSHSEE (National Senior High School Entrance Examination) and NCEE (National College Entrance Examination) on secondary level education, varies along social development, and very possibly the variation would continue. The public complaints over the matter would change with the variation of the policies, whether English is believed to be over-heated or under-estimated.

Language and culture are related, and there would be connections between English language education and the consequent influence of western culture in China. For individuals or for governments, what English brings is not only alphabetical syntagmatic or paradigmatic presentation, but also the culture embodied through the language vehicle. Fanon (1967) pointed out "To speak means to be in a position to use a certain syntax, to grasp the morphology of this or that language, but it means above all to assume a culture, to support the weight of a civilization" (pp. 17-18). In this way, the policies of English language education in China have

(c) 2016 The Author(s). Open Access This article is distributed under the terms of the Creative Commons Attribution 4.0 International License (http://creativecommons.org/licenses/by/4.0/), which permits unrestricted use, distribution, and reproduction in any medium, provided you give appropriate credit to the original author(s) and the source, provide a link to the Creative Commons license, and indicate if changes were made. 
to be weighed carefully, and the paradox of public attitude toward English is an inevitable social occurrence. Simply speaking, "Language itself, in other words, is a political-linguistic-rhetorical construct" (Joseph, 2006, p. 9).

\section{Discussion}

The attempt to control the weight of ELT in 2013

In the year 2013 and 2014, Chinese governments made two plans of English language tests on secondary level school education. Within 2 years, there were significant changes of thinking towards the weight of English in examination system. Weight decreased and then weight regained, the changes within recent years provide a case of foreign language policy for observation from mainland China.

On October $21^{\text {st }}$, 2013, Beijing Municipal Commission of Education sketched The Reformation Program of National Senior High School Entrance Examination in 20142016 (Exposure Draft) and The Reformation Program of College Entrance Examination in 2014-2016 (Exposure Draft). According to these two drafts, the marks of English test would be decreased from 120 to 100 in National Senior High School Entrance Examination (NSHSEE), and from 150 to 100 in National College Entrance Examination (NCEE). The two drafts were expected to be executed since 2016 in Beijing municipal basic education system. English test for NCEE would be implemented by the way of "socialized" examination system twice a year, that is, the English tests would not be organized by the official school education system any longer. Students could take participate in the tests more than one time during the whole process of high school education, and the NCEE would take account in the highest score. Besides, the marks of Chinese language test would be increased from 120 to 150 in NSHSEE, and from 150 to 180 in NCEE; while the marks of Mathematics would remain the same as before.

On the webpage of Beijing Municipal Commission of Education (2013), it defines the nature and status of English language education as follows:

The discipline of English language education should stress the practical application of language, and return to the position where it should be. We should reduce the weight of English scores in NCEE, and implement the socialized examination system which will be held twice a year. The meaning of English test is confined to checking the basic knowledge and basic skills, and reflecting the basic requirements of the curriculum standard.

Half a month later, The Decision on Major Issues Concerning Comprehensively Deepening Reforms was issued on the Third Plenary Session of 18th Central Committee of the Communist Party of China, which was held during November $9^{\text {th }}$ to $12^{\text {th }}, 2013$. In The Decision, the 42th item is about the reformation of education, which indicates that Chinese basic education development should "keep shaping people's morality, strengthening the education of socialist core value system and perfecting the Chinese excellent cultural tradition" (Xinhuanet, 2013). About the assessment, it is pointed out: "subjects like foreign languages should be implemented with socialized examination system and the tests should be taken more than once a year" (Xinhuanet, 2013).

From Beijing Municipal Commission of Education to Central Committee of the Communist Party of China, there was a tendency of changing the then system of 
English language education in mainland Chinese secondary education, to emphasize the application, to vary the testing methodology, and to control the educational weight.

The policy change and the weight regained in 2014

The disciplines of Chinese, Mathematics and English are the main subjects in NSHSEE and NCEE, and naturally in the whole Chinese basic education system. Compared with that, Physics, Chemistry, Biology, Geography, History, Politics and other subjects are in a relatively minor position, and their weight in NSHSEE and NCEE are lower than that of Chinese, Mathematics and English. According to the official blueprint of reformation in 2013, the changes of the weight of these three subjects can be understood by the following Tables 1 and 2.

The reformation program of Beijing municipality would be an example for whole Chinese basic education to follow, which has been recognized by the Third Plenary Session of $18^{\text {th }}$ CPC Central Committee. The other provinces would make relevant reformation schemes in the following years, and the common point of these reformation schemes was to reduce the weight of English marks in NSHSEE and NCEE.

On September $3^{\text {rd }}, 2014$, The State Council of the People's Republic of China issued The Direction on the Implementation of Deepening the Reform of the System of Examination and Enrollment. In the second part of The Direction (The State Council of the People's Republic of China, 2014), the question of ELT in NCEE is clearly pointed out:

It is supposed to reform the testing design of disciplines in high school, and to strengthen the connection between NCEE and senior high school education. The total points of NCEE are made of marks of Chinese, Mathematics and Foreign Language, and the marks of other three subjects by choice. The subjects and testing marks of Chinese, Mathematics and Foreign Language in NCEE keep the same as before. There will be no distinction of science and arts in NCEE, and there will be two opportunities for Foreign Language examination.

In The Direction, the weight of ELT on secondary level regained its importance as before, that is, keeping the same weight as Chinese and Mathematics, and together holding the three most important subjects in NCEE, which could be understood from the following Table 3.

The public paradox in mainland China concerning ELT

With the issue of ELT in school education, the history of Chinese policy is "emphasis-de-emphasis- re-emphasis", that is, firstly increasing the weight of English language in educational system since 1970s, and then trying to decrease it in the new century, while regaining its significance in education as before so far. The official trilogy of ELT makes an interesting case of language policy change, as interesting as the attitude of Chinese

Table 1 The proposed plan of NSHSEE in Beijing in 2013

\begin{tabular}{llll}
\hline & \multicolumn{2}{l}{ The three major subjects in NSHSEE } & \\
\cline { 2 - 4 } & Chinese & Mathematics & English \\
\hline Before 2016 & 120 points & 120 points & 120 points \\
After 2016 & 150 points & 120 points & 100 points \\
\hline
\end{tabular}


Table 2 The proposed plan of NCEE in Beijing in 2013

\begin{tabular}{|c|c|c|c|c|}
\hline & \multicolumn{4}{|c|}{ The three major subjects in NCEE } \\
\hline & & Chinese & Mathematics & English \\
\hline \multirow[t]{2}{*}{ Before 2016} & Arts & 150 points & 150 points & 150 points \\
\hline & Science & 150 points & 150 points & 150 points \\
\hline \multirow[t]{2}{*}{ After 2016} & Arts & 180 points & 150 points & 100 points \\
\hline & Science & 180 points & 150 points & 100 points \\
\hline
\end{tabular}

public toward English language and English language education, that is, "accusing-whilelearning", complaining about the various English tests but never giving it up.

Generally it is regarded that the English test reform is based on the complaint that "English is over heated in China" for a long time, and that English language teaching is "time consuming" with "low efficiency" resulting in the consequence of "deaf-mute English" in the whole Chinese education system. Therefore, reformation of the English test should be a matter of urgency, and the reformation would reasonably promote the equalization of the whole education system, which is one of the most important issues for Chinese government to deal with in education.

After the Cultural Revolution in 1960s and 1970s, China picked up the NCEE. In 1978, marks of English test were just taken as a reference and were not taken into the total points together with Chinese, Mathematics, etc. After 1978, it started to be accounted in the total points of NCEE bit by bit. Since 1979, it began to be gradually increased by 10, 20, 50, $75 \%$ in proportion, and English test marks was not $100 \%$ included in total points of NCEE until the year 1983. The current pattern is that English is equal in weight with Chinese and Mathematics, that is, with the maximum scores of 120 in NSHSEE and 150 in NCEE. According to the direction of Beijing's reformation program and The Decision by the Communist Party of China, from the year 2016 the proportion of English test marks in total points of Chinese basic education system would be gradually decreased to $83 \%(100 / 120), 67 \%(100 / 150)$, even $56 \%(100 / 180)$. The possible decrease of proportion in the near future and the increase of proportion after 1978 make a historical comparison in China, and thus an example of language education policy change in the world.

After the importance of English language in mainland China is highlighted, the blame on English language education has never stopped. English tests have to be taken in NSHSEE, NCEE, and the National Graduate Record Examination for both master and doctorate programs. It will be in and out of schools, for even after graduation an employee still needs to take it in the professional development, for promotions and raises. In 1985, the Chinese Ministry of Education issued The College English Syllabus, which requires key university undergraduates achieve certain level of English language proficiency. Since then College English Test Band 4 and Band 6 (CET-4/6) became one of the most important tests in Chinese tertiary education. In 1991, the Chinese Ministry

Table 3 The decided plan of NCEE across China in 2014

\begin{tabular}{llll}
\hline & \multicolumn{2}{l}{ The three major subjects in NCEE } & \\
\cline { 2 - 4 } & Chinese & Mathematics & English \\
\hline Since 2017 & 150 points & 150 points & 150 points \\
\hline
\end{tabular}


of Personnel, now the Chinese Ministry of Human Resources and Social Security, issued the official rules and regulations on employment and evaluation concerning foreign language proficiency. This official notice stressed the English language examinations should be taken for employees who work in government or government-related working units. While the tests of English are flooding, there is always a problem, that is, English language is too difficult to be mastered. Naturally people complain that English is overheated, English language teaching is time consuming with low efficiency, and the consequence are always of the deaf-mute English. However, Chinese still keep learning English diligently, because English language is connected with all kinds of opportunities. The paradox of the public lasts for over 30 years along with ELT gaining its importance in NSHSEE and NCEE in 1970s.

If English test reform in China is taken as a chess piece, then what we need to think about is the manipulation of this chess piece and the strategy behind it. Walker (1984) noted "Social and political change is both reflected in and constituted by language" (p. 185). The English test reform in Chinese education needs to be understood from the social and cultural perspectives in China. In Chinese education system, English serves both as a tool of communication and as a vehicle of culture, and officially these two sides are to be dialectically united. Unity or harmony may be a fuzzy conceptualization upon this question, while in practice the Chinese government or the Chinese public will have to make choices for English as a tool or as a vehicle.

\section{The official reflections in mainland China concerning ELT}

After three decades of economic development along the reform-and-open policy, Chinese government under the direction of the Communist Party of China is considering the reorientation of the English language and English language education. In 2004 an article "To Consider about Redirection of Foreign Language Education in China" was published in the magazine Qiushi Journal. The article proposes to cut off school English teaching hours and to lower down the weight of English test marks in NCEE, and the proposition is based on the logic that English is over-heated in China, that English language education is time-consuming with low efficiency, and that the problems surrounding English language and English language education in China would inevitably produce harm on mother tongue proficiency, that is, Chinese language acquisition (Tu, 2004, p. 50). Simple though the idea seems, the impact can never be over estimated. The estimation of the impact of this article is not base on the academic achievement of the author, or the logical integrity of the discussion, but on the background of the journal itself which serves as the organ of the Central Committee of the Communist Party of China. As is described on the English Edition of Qiushi Journal (2014):

Founded on July 1, 1988, Qiushi Journal is the organ of the Central Committee of the Communist Party of China (CPC). It is the most influential and authoritative magazine devoted to policy-making and theoretical studies, with a circulation of 1.26 million in 2010.

The highest status of Qiushi Journal in Chinese politics requires the highest level of contributors, which is noted on the English Edition of Qiushi Journal (2014): 
Qiushi Journal has a legion of eminent authors who mainly come from government departments and academia. About $60 \%$ of the articles are written by the Party and state leaders and senior officials at the ministerial or provincial level. Famous scholars and research fellows with China's think tanks and academic institutions are also among the contributors.

From above we can see that the issue of English language education is indeed a serious question in China; otherwise the article would not be published in Qiushi Journal for the Communist Party of China, and literally the Chinese government to think about it. When the importance of the issue is recognized nationally, it should be studied in a systematic and scientific way and be supported by enough sounding evidence. While the article published in Qiushi Journal seems giving us the old-fashioned saying, that is, ELT in China is time consuming and not so efficient as expected, which is commonsensical among the public. In addition, there seems a need for us to think more about the issue, for Qiushi Journal usually is concerned with macro issues across China. This direction is clearly stated in the English Edition of Qiushi Journal (2014):

While reporting on and guiding China's political, economic and social life, Qiushi Journal gives large space to theoretical analysis and review of China's progress, contributing to the enrichment of the theory about development with Chinese characteristics, which is vital to better and faster development of the Chinese society.

In this sense the article "To Consider about Redirection of Foreign Language Education in China" published in Qiushi Journal should be given macro-oriented interpretation in context of Chinese social development.

English is not the official language or the universal second language in mainland China; it serves as a foreign language in Chinese context, thus lacking learning environment and application opportunities. After some certain stages of learning at school, it would be forgotten soon, which causes the phenomenon of "fossilization" and consequently criticism of "time-consuming with low efficiency" in school education.

\section{The issue of English as a foreign language in China's development}

What English language and English language education bring to China, first of all, are the benefits for Chinese historical progress, which could be supported by the progress gained through the reform-and-open decades. Secondly, the interests of ELT might lead to the other way round, which might be against the political direction of Chinese government and would consequently be troublesome for policy makers.

In the words of Troike (1977, p. 2):

From a minor language in 1600, English has in less than four centuries come to be the leading language of international communication in the world today. This remarkable development is ultimately the result of 17th, 18th, and 19th century British successes in conquest, colonization, and trade, but it was enormously accelerated by the emergence of the United States as the major military world power and technological leader in the aftermath of World War II. The process was also greatly abetted by the expenditure of large amounts of governmental and private 
foundation funds in the period of 1950-1970, perhaps the most ever spent in history in support of the propagation of a language.

From this we can see that English is not an important language in the world before the 17th Century. That English became a lingua franca is the consequence of composite influences of military, politics, economy and culture in the process of colonial and post-colonial history.

It is in this sense that English language and English language education serve better the power and interests of the colonial and new colonial countries. Therefore for Western countries, the spread of the English language and the promotion of English language education become a channel of global expansion. To some degree this could explain why English language can be an indispensible intermediary in various fields in the world, and why people's passion for English language in education never retreats. The promising opportunities behind English as a lingua franca are the very reason of the enthusiasm for English language education. English language teaching and learning is basically "a series of acts of identity in which people reveal both their personal identity and their search for social roles" (Le Page and Tabouret-Keller, 1985, p. 14).

Generally speaking, English language and English language education play a great role in Chinese reform-and-open history, for it helps spread the western culture, particularly the advanced science and technology, broaden people's horizons, and boost Chinese economic development, which should be the very reason for Chinese government to keep the same policy of ELT in school education in 2014, that is, keeping the same weight of English as that of Chinese and Mathematics. On the other hand, the problem Chinese have to consider about is the colonial and new colonial cultural background of English language and English language education, which is particularly embodied in the western values in English language and its educational process, and which would produce some negative side effects in the field of ideology, and probably in the field of economy. English is seen as a "Trojan horse" in this sense, implanted in the process of ELT.

Almost a century ago, Sapir (1924, p. 154) warned about the ignorance of the intimate relationship between language and ways of thinking:

To a far greater extent than the philosopher has realized, he is likely to become the dupe of his speech-forms, which is equivalent to saying that the mould of his thought, which is typically a linguistic mould, is apt to be projected into his conception of the world. Thus innocent linguistic categories may take on the formidable appearance of cosmic absolutes.

Language and language users' conception of the world are closely connected, and language choice means certain influence of a different culture. In the mainland Chinese history of open-and-reform decades, English language and English language education help change Chinese people's conception of the world to some extent. The change is positive in Chinese economic growth from an underdeveloped country to an emerging power, and the change might be negative in Chinese cultural development if not carefully considered. Specifically, Pennycook (1992, p. 67) pointed out: 
Culture here refers to people's ways of making sense of their lives, where such sensemaking is understood in terms of productive signifying practices that are organized in various conventionalized ways. Such practices occur always within particular social and historical relations of power, and thus we are able to speak of cultural politics as a struggle over different meanings.

\section{The dilemma of the official trilogy and public paradox}

Chinese government under the direction of the Communist Party of China had the intention of cooling down the English fever before the year 2014, which can be seen from the policy of Beijing Municipal Commission of Education. However the intention of cooling down ELT was negated in no more than 1 year by The State Council of the People's Republic of China, and weight of ELT on the secondary level in mainland China was thus regained. The plot of this trilogy reflects the theme that English serves as a tool or as a vehicle, or simply speaking, "a struggle over different meanings" (Pennycook, 1992, p. 67). It is the same for the public paradox when complaining about the abuse of English tests, while trying their best to study English.

Actually, the attempt to decrease the weight of ELT in school education has seen a trial in the NCEE reformation program in Jiangsu province years before. Jiangsu province decreased the weight of English in NCEE from 2008, as is shown in Table 4.

In the trial of Jiangsu province, English counts 40 points or 80 points less than Mathematics or Chinese in corresponding direction of Arts or Science, taking the proportion of 67 or $75 \%$ by comparison, which means that English is much less important than Mathematics or Chinese in school education. The paradox is that English is still paid much attention by the students, for future English tests in College or for future English uses at abroad. In fact, the reduction of weight of English in NCEE does not reduce the enthusiasm of learning English.

Chinese enthusiasm toward English is not to be weakened, considering the roles English language plays at home and abroad. The motivations of Chinese people and the attitudes held by Chinese governments are complicated, for English as an intermediary tool of communication or as a loaded vehicle.

This issue of the culture politics of ELT could be understood from the explicit or implicit interests of English language and English language education. Based on the three rights in the theory of imperialism by Johan Galtung, Robert Phillipson (1992, p. 273) proposes the three powers of English in world communication, as is shown in Table 5.

For the innate power, the significance of English is exaggerated, and English is seen as so-called god-given, civilized, or noble. In this way English naturally serves as the carrier of the essence of the culture of human beings and as the intermediary of the

Table 4 The maximum marks of Chinese, Mathematics and English of NCEE in Jiangsu's trial

\begin{tabular}{|c|c|c|c|}
\hline & \multicolumn{3}{|c|}{ The three major subjects in NCEE } \\
\hline & Chinese & Mathematics & English \\
\hline Arts & $160+40$ points & 160 points & 120 points \\
\hline Science & 160 points & $160+40$ points & 120 points \\
\hline
\end{tabular}


Table $\mathbf{5}$ The three powers of English in the theory of linguistic imperialism

\begin{tabular}{llll}
\hline Three types of power & & \multicolumn{2}{l}{ Three types of power of English } \\
\hline Innate power & being-power & English is & English-intrinsic \\
Resource power & having-power & English has & English-extrinsic \\
Structural power & position-power & English does & English functional \\
\hline
\end{tabular}

communication of world institutions. English is indeed the most important language nowadays in fields of education, science, diplomacy, etc., and English language education is consequently regarded as a promising discipline in or out of schools. For the resource power, the significance of English is guaranteed materially or immaterially. Phillipson (1992) claimed: "English has both material resources (trained teachers, teacher trainers, teaching materials, literature, dictionaries, multinational publishers, computers and software, BBC English by Radio and TV, low-priced books schemes, etc.) and immaterial resources (knowledge, skills, know-how via its 'experts', etc.)" (p. 277). The innate power and the resource power finally consolidate the structural power of English, that is, about what English can bring to English users and learners. This question is related to one aspect of the cause of the trilogy of mainland Chinese government and the paradox of the public, for English is really important to the economic growth and opportunity seeking. In conclusion, "to improve and extend the use of English as a gateway to better communications, better education, and so a higher standard of living and better understanding" (Makerere Report, 1961, p. 47).

Observed from the colonial and new-colonial history of English language spread and English language education promotion, English has a potential and inevitable problem of being a "Trojan horse". What English can bring to China is in this sense "some benign, some pernicious" (Phillipson, 1992, p. 3), because English may give China, if not carefully considered, "a benevolent bonus or creeping cancer of modernity" (Phillipson, 1992, p. 11). This thinking of the possible disadvantage of English language and English language education is probably the other aspect of the official trilogy on the issue of ELT in mainland China.

The dilemma of the official trilogy and public paradox in mainland China concerning ELT is a case of struggling over the questions of what English is, what English has, and what English does. In other words, "cultural and political issues are interwoven with language policies” (Gopinathan, 1980, p. 177).

\section{Summary}

After English fevers over 30 years in mainland China, the complaints on English policy hum and beep among the public. Will the English fever cease and will the complaint stop? The answer would be very possibly negative, the official position on the matter of English language education will possibly swing, and the public paradox of this issue will possibly continue.

For the policy makers, the positive and negative aspects of English language and English language education have to be balanced on the way of Chinese development materially and immaterially. English as a tool helps drive the wheels of Chinese history of modernization and prosperity, while English as a vehicle might bring effects benign or pernicious, resulting in bonus or trouble. Thus the to-be-or-notto-be hesitation of Chinese government on the issue of English language and 
English language education will lead to the bounces of the policy making. English in China serves as a tool in communication may be value-free; on the other hand, "Linguistic creativity ... cannot be understood apart from the ideological meanings and values that fill it" (Voloshinov, 1973, p. 98).

\section{Competing interests}

The authors declare that they have no competing interests.

Received: 30 May 2016 Accepted: 20 September 2016

Published online: 26 September 2016

\section{References}

Beijing Municipal Commission of Education. (2013). The reformation program of National Senior High School Entrance Examination in 2014-2016 (exposure draft) and The reformation program of College Entrance Examination in 2014-2016 (exposure draft). http://www.bjedu.gov.cn/publish/portal27/tab1654/info34769.htm. Accessed 21 October 2013.

English Edition of Qiushi Journal. (2014) About Qiushi Journal. http://english.qstheory.cn/about/201109/t20110919_ 110860.htm. Accessed 20 September 2014.

Fanon, F. (1967). Black skin white masks. New York: Grove.

Gopinathan, S. (1980). Language policy and education: A Singapore perspective. In E. Afendras \& E. C. Kuo (Eds.), Language and society in Singapore. Singapore: Singapore University Press, 175-202.

Joseph, J. E. (2006). Language and politics. Edinburgh: Edinburgh University Press Ltd.

Le Page, R., \& Tabouret-Keller, A. (1985). Acts of Identity. London: Cambridge University Press.

Makerere Report. (1961). Report on the Conference on the Teaching of English as a Second Language. Entebbe: Commonwealth Education Liaison Committee.

Pennycook, A. (1992). The cultural politics of teaching English in the world. (Unpublished doctoral dissertation). University of Toronto, Toronto, Canada.

Phillipson, R. (1992). Linguistic imperialism. Oxford: Oxford University Press.

Sapir, E. (1924). The grammarian and his language. American Mercury, 1, 149-155. (Repr. In Sapir 1949, 150-159). Sapir, E (1949). Selected Writings in Language, Culture, and Personality. ed. by David G. Mandelbaum. Berkeley and Los Angeles: University of California Press.

The State Council of the People's Republic of China. (2014). Initiation of trial of reform of the system of examination and enrollment (complete version). http://www.chinanews.com/edu/2014/09-04/6561619_2.shtml. Accessed 9 September 2014

Troike, R. C. (1977). The Future of English (Editorial). Linguist Rep, 19(8), 2.

Tu, Y. (2004). To consider about redirection of foreign language education in China. Qiushi J, 6, 50

Voloshinov, V. N. (1973). Marxism and the Philosophy of Language, transl. by Ladislav Matejka and I. R. Titunik. Cambridge, MA and London: Harvard University Press.

Walker, R. B. J. (1984). World Politics and Western Reason: Universalism, Pluralism, Hegemony. In R. B. J. Walker (Ed.), Culture, Ideology and World Order. Boulder, Coll: Westview Press.

Xinhuanet. (2013). Furthering the educational reform according to the decision on major issues concerning comprehensively deepening reforms by CPC. http://news.xinhuanet.com/politics/2013-11/15/c_118164467.htm. Accessed 2 September 2015.

\section{Submit your manuscript to a SpringerOpen ${ }^{\circ}$ journal and benefit from:}

- Convenient online submission

- Rigorous peer review

- Immediate publication on acceptance

- Open access: articles freely available online

- High visibility within the field

- Retaining the copyright to your article 